\title{
Effectiveness of Pfizer-BioNTech Vaccine Against COVID-19 Associated Hospitalizations among Lebanese Adults $\geq 75$ years- Lebanon, April-May 2021
}

Zeina Farah ${ }^{1}$, Nadine Haddad ${ }^{1}$, Hala Abou El Naja ${ }^{1}$, Majd Saleh ${ }^{1}$, Pamela Mrad ${ }^{2}$, Nada Ghosn ${ }^{1}$; ${ }^{1}$ Ministry of Public Health, Epidemiological Surveillance Program, Beirut, Lebanon, ${ }^{2}$ Consultant, Epidemiological Surveillance Program, Beirut, Lebanon

\section{Abstract \\ Introduction}

In Lebanon, the nationwide vaccination against COVID-19 was launched in February-2021 using Pfizer-BioNTech vaccine and prioritizing elderly, persons with comorbidities and healthcare workers. Our study aims to estimate the post-introduction vaccine effectiveness (VE) of Pfizer-BioNTech in preventing COVID-19 hospitalization among $\geq 75$ years in Lebanon.

\section{Methods}

A case-control study design was used. Cases were Lebanese, $\geq 75$ years and hospitalized with positive PCR result during April-May 2021. Cases were randomly selected from the COVID19 database of the Epidemiological Surveillance Unit(ESU) at the Ministry of Public Health(MOPH). Each case was matched by age and locality to 2 controls. Controls were hospitalized, non-COVID-19 patients with negative PCR result, randomly selected from the MOPH hospital admission database. VE was calculated for fully and partially vaccinated, using multivariate conditional logistic regression analyses.

\section{Results}

345 cases and 814 controls were recruited. Half were females, with a mean age of 83 years. 14 cases(5\%) and 143 controls(22\%) were fully vaccinated. Bivariate analysis showed significant association with: gender, month of confirmation/admission, general health, chronic medical conditions, main income source and living arrangement. After adjusting for month of admission and gender, multivariate analysis yielded a VE of $82 \%$ (95\%CI $=69 \%$ 90\%) against COVID-19 associated hospitalization for those fully vaccinated and 53\% $(95 \% \mathrm{CI}=23 \%-71 \%)$ for those partially vaccinated ( $\geq 14$ days of first or within 14 days of second dose).

\section{Conclusions}

Our study showed that Pfizer-BioNTech vaccine is effective in reducing risk for COVID-19associated hospitalization in Lebanese elderly( $\geq 75$ years). Additional studies are warranted to 
medRxiv preprint doi: https://doi.org/10.1101/2022.01.19.22269514; this version posted January 24, 2022. The copyright holder for this preprint

(which was not certified by peer review) is the author/funder, who has granted medRxiv a license to display the preprint in perpetuity.

All rights reserved. No reuse allowed without permission.

explore vaccine effectiveness in reducing hospitalization in younger age groups, as well as in reducing covid-19 infections. 


\section{Introduction}

Since its emergence in December 2019, the severe acute respiratory syndrome coronavirus 2 (SARS-CoV-2) has taken a tremendous toll on the population worldwide. By 4 May 2021, there have been over 153 million cases and 3.2 million deaths globally from COVID-19(1). The implemented non-pharmacological interventions affected the daily lives of billions around the world, resulting in devastating socio-economic repercussions - the biggest challenge that humanity ever faced since World War II(2).

In response to this pandemic, considerable efforts were put globally into developing effective and safe drugs and vaccines against SARS-CoV-2(3). Candidate vaccines were introduced with differing indications, contra-indications and adverse events - each with a specific efficacy in preventing SARS-CoV-2 infection, severe outcomes, and death(4). Hence, it is of a paramount importance to evaluate the post-introduction effectiveness of the approved and marketed vaccines.

In Lebanon, a total of 529,205 COVID-19 confirmed cases and 7,368 related deaths were reported as of 4 May 2021 since the detection of the first case on 21 February 2020(5). In January 2021, the Lebanese Ministry of Public Health(MOPH) issued its National Deployment and Vaccination Plan for COVID-19 vaccines(NDVP) in which priority target groups were selected based on specific risk factors: age, comorbidity, and occupation in line with the World Health Organization(WHO) Strategic Advisory Group of Experts on Immunization (SAGE) recommendations(6) . On 14 February 2021, almost a year after the beginning of the outbreak, the national vaccination was rolled out upon the arrival of the first batch of Pfizer-BioNTech vaccine(7). On 24 March 2021, the country received the first batch of AstraZeneca vaccine, hence putting forward the deployment of the national vaccination plan. As of 6 May 2021, a total of 498,722 vaccine doses of various types (Pfizer-BioNTech, AstraZeneca, Sputnik V, SinoPharm) were administered as reported through the InterMinisterial and Municipal Platform for Assessment, Coordination and Tracking (IMPACT) platform(7). Pfizer-BioNTech vaccine was used for residents aged 75 and above with a time interval of 21 days between the 2 doses and a coverage of $37 \%$ for 2 doses, as of 6 May 2021.

As the nationwide vaccination progresses, it is vital to study the vaccine effectiveness in the community as emphasized in the NDVP. Particularly, the national plan mentions the role of 
the Epidemiological Surveillance Unit(ESU) in studying vaccine effectiveness in order to guide vaccination policies and Public Health and Social Measures(6).

Hence, our study aimed to estimate the post-introduction effectiveness of Pfizer-BioNTech COVID-19 vaccine against COVID-19 hospitalization among Lebanese adults $\geq 75$ years.

\section{Methods}

\section{Study design}

A case-control (CC) study design was conducted using structured questionnaires conducted via phone call interviews(10). Our sample size was calculated using the precision method with $90 \%$ vaccine effectiveness for full vaccination and $40 \%$ vaccine coverage, a $\pm 5 \%$ precision and a type 1 error of 0.05. A minimum sample size of 318 cases and 636 controls was needed(8). The minimal sample size was multiplied by $50 \%$ to account for non-response and refusals. Proportionate matching with 1:2 cases to control ratio was conducted according to age group ([75-85[; [85-95)) and locality (governorate) of residence.

\section{Study population}

The COVID-19 surveillance database of the ESU-MOPH was screened to select confirmed cases reported as Lebanese, $\geq 75$ years, hospitalized and diagnosed with COVID-19 by Real Time-Polymerase Chain Reaction between April and May 2021. A random sample of 742 cases was drawn from the selected sampling frame and contacted to verify whether they meet our study inclusion criteria. Cases not meeting one of the inclusion criteria were discarded from our analysis.

Controls were selected randomly from the MOPH hospital admission database(of uninsured individuals covered by the $\mathrm{MOPH}$ ) which comprises around $50 \%$ of all hospitalizations in Lebanon(9). The selected controls were Lebanese, $\geq 75$ years old and hospitalized between April and May 2021 with admission diagnosis related to all International Classification of Diseases (ICD-10) chapters excluding the COVID19 code. During our study period, any hospitalization due to causes other than COVID-19 required a negative RT-PCR prior to admission, so it was assumed that the negative status of controls is ascertained. Controls were later excluded if the investigation showed they do not meet one of our study inclusion criteria. 


\section{Variables}

A structured questionnaire was used including socio-demographic information(age, gender, place of residence and main source of income), living conditions(number of household members, number of rooms and living arrangement), health conditions in the 12-month period prior to admission(perception of general health status, presence of comorbidities and ability to walk and climb), hospitalization status(duration of hospitalization, admission to Intensive Care Unit(ICU), duration of stay at ICU, oxygen therapy, intubation, and discharge status) in addition to cognitive variables (ability to read and performing calculations). Further, crowding index was computed by dividing the number of household members by the number of rooms. The date of PCR test result confirmation was available for all cases. However, the date of admission was used for controls as it was available in the MOPH admission database. This time variable was considered a confounding factor as both the vaccination coverage and COVID-19 incidence show time trends during the study period $(7,10)$. Three categories for hospital stay were generated: $<3$ days, 3 to 7 days and above 7 days.

Participants self-reported their vaccination status by indicating their vaccination dates according to the received SMS from the MOPH vaccination platform. Vaccination data was considered only for participants reporting exact dates of vaccination. Vaccination status included 4 categories: 1)“Unvaccinated" defined as no receipt of Pfizer- BioNTech vaccine before confirmation/admission, 2)Single-dose vaccinated $<14$ days before confirmation/admission, 3)"Partially vaccinated" defined as receipt of 1 dose of PfizerBioNTech vaccine $\geq 14$ days before confirmation/admission or 2 doses, with the second dose received $<14$ days before confirmation/admission 4)"Fully vaccinated" defined as receipt of 2 doses of the vaccine with the second dose received $\geq 14$ days before confirmation/admission.

\section{Data management}

Collected data was digitalized using DHIS2 tracker program and analyzed using $\mathrm{R}$ version 4.0.4 and R studio version 1.4.1103. For the VE analysis, fully and partially vaccinated participants were compared to unvaccinated subjects. Univariate descriptive statistics was used to assess the distribution of covariates among participants and identify potential confounding factors. Characteristics of cases and controls were compared using Chi-square tests or Fisher's exact tests for categorical variables and Student's t-test or Wilcoxon rank- 
sum tests for continuous variables. For the final selection of potential confounders to include in the logistic regression model, the "change-in-estimate" approach was used (8). Covariates whose adjustment changed the crude odds ratio by $\geq 5 \%$ were included in the final models. VE was estimated using conditional logistic regression following the below formula(8):

$\mathrm{VE}=(1-$ matched, adjusted odds ratio for vaccination $) \times 100 \%$

The $95 \%$ Confidence Intervals(CIs) of VE were calculated as $1-\mathrm{CI}_{\mathrm{OR}}$, where $\mathrm{CI}_{\mathrm{OR}}$ is the confidence interval of the odds ratio estimates.

\section{Ethical approval}

The study was approved by the Institutional Review board of the Rafik Hariri University Hospital. Informed consent was obtained from study subjects prior to participation. 


\section{Results}

\section{Study population}

Between April $1^{\text {st }}$ and May $31^{\text {st }} 2021,742$ cases and 1,561 controls were contacted for the study. However, due to either being excluded for not fitting case/control definition(34\%; $23 \%)$, no reply $(16 \% ; 20 \%)$ or refusal to participate $(4 \% ; 5 \%)$, the retained number of participants was 345 cases to 814 matched controls(Figure 1).

The mean age of participating cases and controls was $83.1 \pm 5.6$ and $82.8 \pm 5.7$ years, respectively. The highest proportion of cases and controls resided in Mount-Lebanon governorate $(37 \% ; 39 \%)$. Cases had an equal proportion of females and males $(50 \%)$; however, the control group had a significantly higher proportion of females $(57 \%)(P=.03)$ (Table 1).

Concerning household arrangement, cases had a greater number of rooms (3.4 \pm 1.4$)$ compared to controls $(3.0 \pm 1.2)$ and a higher number of household members $(2.4 \pm 1.7)$ compared to controls $(2.0 \pm 1.9)(P<.001)$. Most cases and controls $(87 \% ; 76 \%)$ lived with family members. No significant differences were noted for the crowding index between our comparison groups $(P=.64)$ (Table 1).

For the vast majority in both groups, family support was the main source of income. However, cases (11\%) had more retirement pensions than controls (2\%) (Table 1).

Cases $(54 \%, n=184)$ were significantly more likely than controls $(32 \%, n=233)$ to perform calculations without difficulty. They were also more likely to read and write without difficulty (49\% of cases as compared to $33 \%$ among controls, $P<.001$ ). On the other hand, the proportion of subjects reporting inability to read and write was higher among controls (43\%, $\mathrm{n}=329)$ than cases $(27 \%, \mathrm{n}=92)$ (Table 1$)$.

The general health status of the cases and controls in the 12 months prior to admission was also significantly different $(P<.001)$ and was mostly good $(44 \%$ for cases and $36 \%$ for controls) followed by fair health status ( $26 \%$ cases and $32 \%$ for controls). $41 \%$ of cases reported no difficulty walking, climbing up and down stairs prior to admission, while $34 \%$ of controls did not have the ability to conduct this task (Table 1). 
Majority of cases and controls had at least one underlying condition ( $85 \%$; $92 \%)(P=.001)$. The underlying conditions reported for both cases and controls were mostly hypertension $(70 \% ; 76 \%)$ followed by heart diseases $(50 \% ; 66 \%)$, and diabetes $(43 \% ; 47 \%)$ respectively (Table 1).

\section{Hospitalization}

As for hospitalization information, the mean duration of hospital stay was significantly higher among cases (11.1 \pm 9.3 days) compared to controls (6.0 \pm 7.0 days). In particular, the length of stay was mostly $>7$ days for cases (53\%) while 3-7 days for controls (60\%). Majority of cases required ICU admission (67\%) with a longer duration of stay (8.5 \pm 7.9 days) while $25 \%$ of controls were admitted to ICU $(P<.001)$ (Table 2).

Furthermore, cases were significantly more likely than controls to require oxygen therapy $(90 \%)$ and intubation $(46 \%)(P<0.001)$. Death upon discharge was significantly higher among cases $(52 \%)$ compared to controls $(10 \%)(P<0.001)$. Among cases, the majority were due to COVID-19(93\%) (Table 2). Of note, no change in the above results was found when restricting the Univariate analysis to participants with complete vaccination data.

\section{Vaccination effectiveness}

Majority of cases and controls reported zero dose of vaccination $(81 \% ; 63 \%), 13 \%$ of cases reported having received one dose of vaccine compared to $11 \%$ for controls, and $5 \%$ of cases reported having two doses compared to $27 \%$ of controls. Majority of cases and controls reported no side effects following $1^{\text {st }}$ dose $(66 \% ; 82 \%)$ and second dose $(67 \% ; 81 \%)$ respectively ( $P=.002$ and .13 respectively) (Table 3$)$.

Taking fully vaccinated individuals as 14 days after second dose, 14 cases (4\%) and 143 controls $(21 \%)$ were fully vaccinated and the crude OR was $0.16(95 \% \mathrm{CI}=0.09-0.28)$. After adjusting for month of admission and gender, multivariate analysis yielded an adjusted OR of 0.18 and a VE of $82 \%(95 \% \mathrm{CI}=69 \%-90 \%)$ (Table 3$)$. For those partially vaccinated, the crude OR was $0.49(95 \% \mathrm{CI}=0.30-0.79)$. After adjusting for month of admission, the adjusted OR was 0.47 and the vaccine effectiveness was $53 \%(95 \% \mathrm{CI}=23 \%-71 \%)$ (Table 4$)$.

On the other hand, there was no significant effect for receiving the first dose of the vaccine within 14 days of confirmation/admission (adjusted $\mathrm{OR}=1.09$ and 95\% $\mathrm{CI}=0.63-1.87$ ). 


\section{Discussion}

Clinical trials have assessed the efficacy of Pfizer-BioNTech vaccine against COVID-19 associated infection; however, monitoring efficacy against COVID-19 associated hospitalization was not possible because hospitalization is a rare outcome among COVID-19 patients(11). Our study supports assessment of COVID-19 hospitalization among a high-risk group. In this analysis of Lebanese $\geq 75$ years old hospitalized between April and May 2021, vaccination with Pfizer-BioNTech was significantly less likely among hospitalized patients with COVID-19 than other conditions. These findings are consistent with available evidence showing reduction in COVID-19 associated hospitalization among vaccinated patients compared to unvaccinated subjects (12)

In this study, multivariate analysis of hospitalized patients $\geq 75$ years revealed that PfizerBioNTech vaccine was associated with significant protection against COVID-19 hospitalization. Effectiveness was $82 \%$ among elderly 75 years and above who were fully vaccinated (14 days after second dose) and 53\% among those who were partially vaccinated (having received 1 dose of vaccine $\geq 14$ days before confirmation/admission or 2 doses, with the second dose received <14 days after confirmation/admission).

Our findings suggest that two doses of Pfizer-BioNTech vaccine at least 14 days after vaccine administration provided a substantial level of protection ( $82 \% \mathrm{VE})$ against hospitalization for elderly individuals ( $\geq 75$ years) in Lebanon between April and May 2021. These results are consistent with previous studies showing similar results, mainly two studies conducted in the United States(US) during the period March-July and February-August 2021 targeting adults, showing the VE of mRNA vaccines (Pfizer-BioNTech and Moderna) against hospitalization to be $86 \%(95 \% \mathrm{CI}=82 \%-88 \%)$ and $80 \%(95 \% \mathrm{CI}=68 \%-87 \%)$ among fully vaccinated aged 65 years and above $(13,14)$.

Moreover, in assessing the impact of one dose of the vaccine, no significant effectiveness within the 14 days of the first dose was detected. This is also in line with results from other studies showing no significant effect in the 14 days after the first dose $(11,15)$.

However, our findings are lower than the VE reported in some studies assessing the effectiveness of mRNA vaccines against COVID19 hospitalization mainly two studies 
conducted during January-March and March-August 2021. These studies targeted adults in the US showing the VE of mRNA vaccines (Pfizer-BioNTech and Moderna vaccines) for fully vaccination to be $94 \%(95 \% \mathrm{CI}=49 \%-99 \%)$ for adults $\geq 65$ years and the VE of PfizerBioNTech vaccine to be $91 \%(95 \% \mathrm{CI}=88 \%-93 \%)$ among adults $\geq 18$ years, respectively $(11,16)$.

As for the effectiveness of partial vaccination, our findings were lower than those reported in a study conducted in the US showing the Pfizer-BioNTech vaccine VE to be $64 \%$ $(95 \% \mathrm{CI}=28 \%-82 \%)$ against hospitalization (after 14 days of first dose or within 14 days of second dose) among adults $\geq 65$ years(11). It was also lower than those reported in other studies assessing the VE against hospitalization after 14 days of one Pfizer-BioNTech dose, showing a VE of $71 \%(95 \% \mathrm{CI}=47 \%-91 \%)$ among elderly $\geq 80$ years in the UK and a VE of $70 \%(95 \% \mathrm{CI}=60 \%-77 \%)$ among people $\geq 16$ years in Canada $(17,18)$

The difference between the study results could be due mostly to the mean age group of this study which is around 83 years, higher in comparison to the other studies. Moreover, the fact that some of these studies were assessing a combination of mRNA vaccines, not only the Pfizer-BioNTech vaccine could have affected the comparison. Other factors to mention include the difference in the study design, evaluated population and inclusion criteria between the different studies as well as the variability in unmeasured confounding factors.

Moreover, our study took place between April and May 2021 where the dominant variant in Lebanon is suggested to be Alpha. In Lebanon, genomic sequencing began in June with Alpha variant being the dominant circulating virus (19); SARS-CoV2 delta variant took over and became the dominant circulating virus in Lebanon starting July 2021. The fact that some VE studies were targeting delta variant, this might have led to the observed differences in VE values when comparing our results to other studies. Therefore, it is very crucial to interpret VE results and cautiously compare them with other international studies taking into account SARS-CoV2 circulating variants at time of study period.

Furthermore, in our study design, targeting elderly individuals above 75 years for both cases and controls, might have affected vaccine intake as well as exposure to infection in the sense that decreased mobility of elderly individuals might have affected the accessibility to vaccination; likewise, elderly individuals, due to their vulnerable conditions, might have 
limited their exposure to their bubble, hence decreasing the risk of exposure to infection during the pandemic. Any of these directions might have biased our VE estimates.

Additionally, majority of cases and controls reported having zero dose of vaccination (90\%; $64 \%$ ) at the time of study, which can be explained by the timeline of vaccine rollout in the country that started in mid-February and that faced delays in initiation due to interruptions in receiving vaccine batches into the country.

On the other hand, important results to be highlighted are the severity of illness of COVID-19 associated hospitalization as compared to non-COVID-19 hospitalizations. This study clearly reveals that although COVID-19 hospitalized patients subjectively have a better rating for their general health status, their prognosis is much worse than non-COVID-19 patients hospitalized with longer durations of stay, significantly higher need for intensive care, oxygen therapy and intubation, and ultimately death.

As vaccination may provide false sense of security, our findings highlight the importance of adhering to public health measures to avoid COVID-19 associated hospitalization where vaccinated individuals are still advised to continue practicing hand hygiene, physical distancing, and mask wearing (20).

\section{Limitations}

The study findings are subject to some limitations. First, The MOPH admission database, from which controls were sampled, is not inclusive of the total target population as it covers hospitalization of citizens who are uninsured and who usually belong to the most deprived segments of the population, such as seasonal workers, farmers, retired and unemployed persons, thus on average an older and poorer population (9). Additionally, vaccine effectiveness estimates might be confounded by certain unmeasured behaviors like adherence to non-pharmaceutical interventions, including mask use or recent attendance of gatherings in addition to some variables like socioeconomic status and prior SARS-COV-2 infection. This might have affected our results as uncontrolled confounders might lead to differences in vaccine uptake, exposure to infection, and development of severe disease implications. 


\section{Conclusion}

Our study showed that Pfizer-BioNTech vaccine is effective in reducing risk for COVID-19associated hospitalization in older adults. These findings reinforce the importance of vaccination, among elderly who are at high risk for COVID-19 hospitalization. Additional studies are warranted to explore vaccine effectiveness in reducing hospitalization in younger age groups, as well as reducing COVID-19 infections taking into account other vaccine products in light of the emergence of new SARS-CoV-2 variants and the increase in the elapsed time since vaccination.

\section{Acknowledgments}

The authors would like to acknowledge the efforts of the ESU teams in helping in data collection and would like to thank all reporting sites for their continuous collaboration with the MOPH. 
medRxiv preprint doi: https://doi.org/10.1101/2022.01.19.22269514; this version posted January 24, 2022. The copyright holder for this preprint (which was not certified by peer review) is the author/funder, who has granted medRxiv a license to display the preprint in perpetuity.

All rights reserved. No reuse allowed without permission.

Figure 1: Selection of study participants and sample size, VE CC study, $\geq 75$ years, Apr-May2021, Lebanon
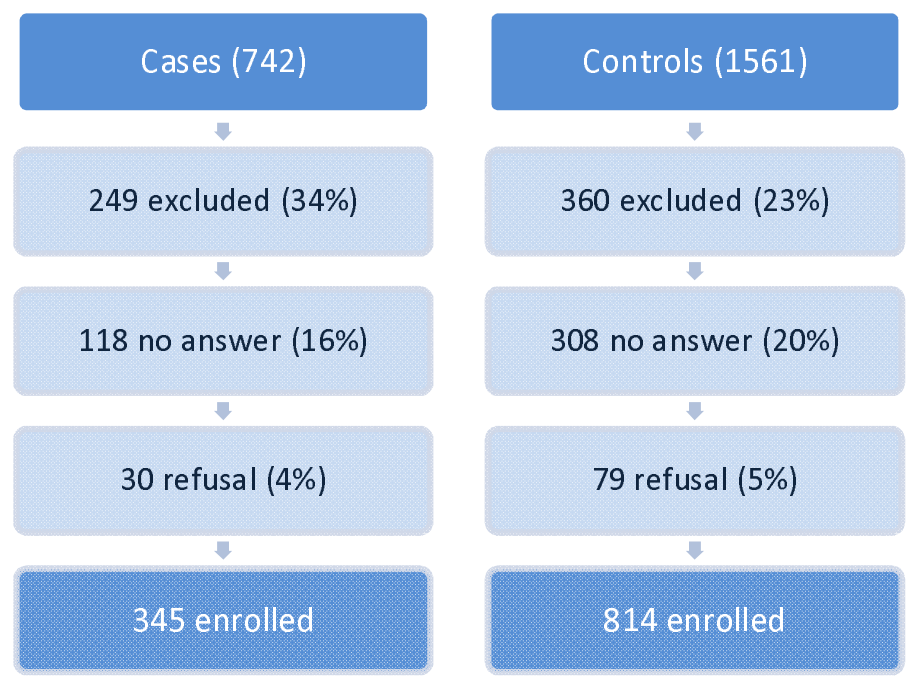

Table 1: Characteristics of Lebanese hospitalized COVID-19 case-patients and controls aged $\geq 75$ years, April-May 2021

\begin{tabular}{|c|c|c|c|}
\hline \multirow{2}{*}{ Characteristics } & \multirow{2}{*}{$\begin{array}{c}\begin{array}{c}\text { Cases } \\
(\mathrm{N}=345)\end{array} \\
\mathrm{n}(\%)\end{array}$} & \multirow{2}{*}{$\begin{array}{c}\begin{array}{c}\text { Controls } \\
(\mathrm{N}=814)\end{array} \\
\mathrm{n}(\%)\end{array}$} & \multirow{2}{*}{ p-value } \\
\hline & & & \\
\hline \multicolumn{4}{|c|}{ Socio-demographic characteristics } \\
\hline Age $($ mean \pm sd $)$ & $83.1 \pm 5.6$ & $82.8 \pm 5.7$ & .53 \\
\hline \multicolumn{4}{|l|}{ Age groups } \\
\hline $75-84$ & $236(68.4)$ & $559(68.7)$ & .98 \\
\hline $85+$ & $109(31.6)$ & $255(31.3)$ & \\
\hline \multicolumn{4}{|l|}{ Gender } \\
\hline Female & $171(49.6)$ & $463(56.9)$ & .03 \\
\hline Male & $174(50.4)$ & $350(43.1)$ & \\
\hline \multicolumn{4}{|l|}{ Place of residence (governorate) } \\
\hline Mount Lebanon & $128(37.1)$ & $318(39.0)$ & .33 \\
\hline Bekaa/Baalbeck-Hermel & $75(21.7)$ & $138(17.0)$ & \\
\hline South/Nabatieh & $64(18.6)$ & $178(21.9)$ & \\
\hline North & $47(13.6)$ & $110(13.5)$ & \\
\hline Beirut & $31(9.0)$ & $70(8.6)$ & \\
\hline \multicolumn{4}{|l|}{ Main income source } \\
\hline Family help & $265(77.5)$ & $646(82.8)$ & $<.001$ \\
\hline Retirement pension & $38(11.1)$ & $19(2.4)$ & \\
\hline Personal savings & $34(9.9)$ & $77(9.9)$ & \\
\hline Financial help (not family) & $4(1.2)$ & $30(3.9)$ & \\
\hline No income & $1(0.3)$ & $8(1.0)$ & \\
\hline \multicolumn{4}{|l|}{ Living conditions } \\
\hline $\begin{array}{l}\text { Number of household member: } \\
(\text { mean } \pm \mathrm{sd})\end{array}$ & $2.4 \pm 1.7$ & $2.0 \pm 1.9$ & $<.001$ \\
\hline Number of rooms (mean $\pm \mathrm{sd})$ & $3.4 \pm 1.4$ & $3.0 \pm 1.2$ & $<.001$ \\
\hline
\end{tabular}


Crowding index (mean $\pm \mathrm{sd})$

Living arrangement

Alone

With Family

With domestic help

Long-term facility
$0.8 \pm 0.6$

24(7.0)

299(87.1)

$17(5.0)$

$3(0.9)$
$0.7 \pm 0.7$

$122(15.1)$

$610(75.5)$

$61(7.5)$

15(1.9)

Health conditions (in the 12 months period prior to admission)

Perception of general health status

$\begin{array}{lcc}\text { Very good } & 61(17.9) & 51(6.4) \\ \text { Good } & 151(44.4) & 290(36.1) \\ \text { Fair } & 87(25.6) & 258(32.1) \\ \text { Poor } & 34(10) & 169(21.0) \\ \text { Very poor } & 7(2.1) & 35(4.4)\end{array}$

Ability to walk, climb up or down stairs alone

Yes, without difficulty

$141(41.2)$

$162(20.4)$

Yes, but with some difficulty

90(26.3)

$161(20.2)$

$<.001$

Yes, but with help or assistance

73(21.4)

202(25.4)

No

$38(11.1)$

271(34.0)

\section{Underlying conditions}

Hypertension

221(69.9)

549(75.6)

.07

Heart disease

$150(50.2)$

Diabetes

$125(42.7)$

Kidney disease

34(12.6)

Lung disease

30(10.9)

Cancer

12(4.4)

Asthma

$10(3.7)$

Rheumatological disorders

$6(2.2)$

$4(1.5)$

Liver disease

$4(1.5)$

History of cancer

$4(1.5)$

448(66.1)

$<.001$

314(47.0)

.24

76(13.0)

.96

111(18.3)

.007

68(11.3)

.002

30(5.2)

.46

45(7.8)

.003

15(2.6)

.44

25(4.3)

.05

Immunodeficiency

6(1.0)

.82

Presence of at least one underlying condition

No

Yes
$50((15.1)$

282(84.9)
65(8.4)

713(91.6)

.001

Cognitive status(in the 12 months period prior to admission)

Ability to read and write

Yes, without difficulty

Yes, but with some difficulty

Yes, but with help or assistance

No

\section{Ability to perform calculations}

Yes, without difficulty

Yes, but with some difficulty

Yes, but with help or assistance

No
$184(53.8)$

$169(49.4)$

$53(15.5)$

28(8.2)

92(26.9)

$50(14.6)$

$21(6.1)$

$87(25.5)$
$250(32.5)$

142(18.5)

48(6.2)

$329(42.8)$

233(31.6)

$<.001$

$<.001$

91(12.3)

53(7.2)

361(48.9) 
medRxiv preprint doi: https://doi.org/10.1101/2022.01.19.22269514; this version posted January 24, 2022. The copyright holder for this preprint (which was not certified by peer review) is the author/funder, who has granted medRxiv a license to display the preprint in perpetuity.

All rights reserved. No reuse allowed without permission.

Table 2: Hospitalization data of Lebanese hospitalized COVID-19 case-patients and controls aged $\geq 75$ years, April-May 2021

\begin{tabular}{|c|c|c|c|}
\hline \multirow{2}{*}{ Characteristics } & $\begin{array}{c}\text { Cases } \\
(\mathrm{N}=345)\end{array}$ & $\begin{array}{c}\text { Controls } \\
(\mathrm{N}=814)\end{array}$ & \multirow{2}{*}{ p-value } \\
\hline & $\mathrm{n}(\%)$ & $\mathrm{n}(\%)$ & \\
\hline \multicolumn{4}{|l|}{ Hospitalization status } \\
\hline \multicolumn{4}{|l|}{$\begin{array}{l}\text { Month of confirmation/ } \\
\text { admission* }\end{array}$} \\
\hline April & $271(78.6)$ & $464(57.0)$ & $<.001$ \\
\hline May & $74(21.4)$ & $350(43.0)$ & \\
\hline \multicolumn{4}{|l|}{ Duration of } \\
\hline \multicolumn{4}{|l|}{ Hospital stay } \\
\hline$<3$ days & 31(9.6) & $160(22.3)$ & $<.001$ \\
\hline 3-7 days & $120(37.0)$ & $426(59.5)$ & \\
\hline$>7$ days & $173(53.4)$ & $130(18.2)$ & \\
\hline \multicolumn{4}{|l|}{ Admission to ICU } \\
\hline Yes & $224(66.9)$ & $180(24.6)$ & $<.001$ \\
\hline No & $111(33.1)$ & $551(75.4)$ & \\
\hline Duration of stay at ICU & $8.5 \pm 7.9$ & $5.8 \pm 5.8$ & $<.001$ \\
\hline \multicolumn{4}{|l|}{ Oxygenotherapy } \\
\hline Yes & 275(90.2) & $175(25.8)$ & $<.001$ \\
\hline No & $30(9.8)$ & $503(74.2)$ & \\
\hline \multicolumn{4}{|l|}{ Mechanical ventilation } \\
\hline Yes & $107(46.3)$ & $40(6.1)$ & $<.001$ \\
\hline No & $124(53.7)$ & 611(93.9) & \\
\hline \multicolumn{4}{|l|}{ Discharge status } \\
\hline Alive & $153(48.3)$ & 711(89.8) & $<.001$ \\
\hline Death & $164(51.7)$ & $81(10.2)$ & \\
\hline \multicolumn{4}{|l|}{ Cause of death ${ }^{\S}$} \\
\hline Due to COVID-19 & $136(93.4)$ & $0(0)$ & $<.001$ \\
\hline Due to other causes & $9(6.2)$ & $70(100)$ & \\
\hline
\end{tabular}

* Month of confirmation for cases and admission for controls

$\S$ Among deaths 
medRxiv preprint doi: https://doi.org/10.1101/2022.01.19.22269514; this version posted January 24, 2022. The copyright holder for this preprint (which was not certified by peer review) is the author/funder, who has granted medRxiv a license to display the preprint in perpetuity.

All rights reserved. No reuse allowed without permission.

Table 3: Vaccination data of Lebanese hospitalized COVID-19 case-patients and controls aged $\geq 75$ years, April-May $2021^{*}$

\begin{tabular}{|c|c|c|c|}
\hline \multirow{2}{*}{ Characteristics } & $\begin{array}{c}\text { Cases } \\
(\mathrm{N}=337)\end{array}$ & $\begin{array}{l}\text { Controls } \\
(\mathrm{N}=695)\end{array}$ & \multirow{2}{*}{ p-value } \\
\hline & $\mathrm{n}(\%)$ & $\mathrm{n}(\%)$ & \\
\hline \multicolumn{4}{|c|}{ Number of received doses prior to admission } \\
\hline Two doses & $18(5.3)$ & $184(26.5)$ & $<.001$ \\
\hline One dose & $45(13.4)$ & $73(10.5)$ & \\
\hline Zero doses & $274(81.3)$ & $438(63.0)$ & \\
\hline \multicolumn{4}{|l|}{$\begin{array}{l}\text { Vaccination status prior to } \\
\text { confirmation/admission }\end{array}$} \\
\hline Fully vaccinated & $14(4.2)$ & $143(20.6)$ & $<.001$ \\
\hline Partially vaccinated & $24(7.1)$ & $79(11.4)$ & \\
\hline Within 14 days of first dose & $25(7.4)$ & $35(5.0)$ & \\
\hline Unvaccinated & $274(81.3)$ & $438(63.0)$ & \\
\hline \multicolumn{4}{|c|}{ Adverse event following first dose } \\
\hline No side effects & $41(66.1)$ & $210(81.7)$ & .002 \\
\hline Minor side effects & $10(16.1)$ & $34(13.2)$ & \\
\hline Moderate side effects & $5(8.1)$ & $10(3.9)$ & \\
\hline Severe & $6(9.7)$ & $3(1.2)$ & \\
\hline \multicolumn{4}{|c|}{ Adverse event following second dose } \\
\hline No side effects & $12(66.7)$ & $145(80.6)$ & 0.13 \\
\hline Minor side effects & $3(16.7)$ & $26(14.4)$ & \\
\hline Moderate side effects & $2(11.1)$ & $5(2.8)$ & \\
\hline Severe & $1(5.5)$ & $4(2.2)$ & \\
\hline
\end{tabular}

Table 4: Pfizer-BioNTech vaccine effectiveness* against COVID-19 among Lebanese hospitalized COVID-19 case-patients and controls aged $\geq 75$ years, April-May $2021(\mathrm{n}=1,032)$

\begin{tabular}{llccc}
\hline $\begin{array}{l}\text { Vaccination } \\
\text { status }\end{array}$ & Cases & Controls & $\begin{array}{c}\text { Unadjusted } \\
\text { OR (95\% CI) }\end{array}$ & $\begin{array}{c}\text { VE against COVID-19 } \\
\text { hospitalization (95\% CI) }\end{array}$ \\
\hline $\begin{array}{l}\text { Fully vaccinated } \\
\text { Partially vaccinated }\end{array}$ & $14(4.2)$ & $143(20.6)$ & $0.16(0.09-0.28)$ & $82(69-90)^{*}$ \\
*Adjusted for month of confirmation/admission and gender & $79(11.4)$ & $0.49(0.30-0.79)$ & $53(23-71)^{* *}$ \\
**Adjusted for month of confirmation/admission &
\end{tabular}


medRxiv preprint doi: https://doi.org/10.1101/2022.01.19.22269514; this version posted January 24, 2022. The copyright holder for this preprint (which was not certified by peer review) is the author/funder, who has granted medRxiv a license to display the preprint in perpetuity.

\section{References}

1. World Health Organization. WHO Coronavirus (COVID-19) Dashboard [Internet]. 2021 [cited 2021 Dec 17]. Available from: https://covid19.who.int

2. BBC news. Coronavirus: Greatest test since World War Two, says UN chief - BBC News [Internet]. 2020 [cited 2021 Dec 17]. Available from:

https://www.bbc.com/news/world-52114829

3. Dong Y, Dai T, Wei Y, Zhang L, Zheng M, Zhou F. A systematic review of SARSCoV-2 vaccine candidates. Signal Transduct Target Ther. 2020 Oct 13;5(1):1-14.

4. Meo SA, Bukhari IA, Akram J, Meo AS, Klonoff DC. COVID-19 vaccines: comparison of biological, pharmacological characteristics and adverse effects of Pfizer/BioNTech and Moderna Vaccines. Eur Rev Med Pharmacol Sci. 2021 Feb;25(3):1663-9.

5. World Health Organization. COVID-19 Daily Brief. Lebanon, country office; 2021.

6. Ministry of Public Health. Lebanon National Deployment and Vaccination Plan for COVID-19 Vaccines [Internet]. 2021. Available from: https://www.moph.gov.lb/userfiles/files/Prevention/COVID19\%20Vaccine/Lebanon\%20NDVP-\%20Feb\%2016\%202021.pdf

7. IMPACT platform. Impact Open Data: Vaccine Statistics [Internet]. 2021 [cited 2021 Dec 17]. Available from: https://impact.cib.gov.lb/home?dashboardName=vaccine

8. World Health Organization. Evaluation of COVID-19 vaccine effectiveness: interim guidance, 17 March 2021 [Internet]. World Health Organization; 2021 [cited $2021 \mathrm{Dec}$ 17]. Report No.: WHO/2019-nCoV/vaccine_effectiveness/measurement/2021.1. Available from: https://apps.who.int/iris/handle/10665/340301

9. Ammar, Walid. Health System and Reform In Lebanon - 2003 [Internet]. 2003. Available from: http://www.moph.gov.lb

10. Ministry of Public Health. Monitoring of COVID-19 Infection In Lebanon-Daily report [Internet]. 2021 [cited 2021 Dec 29]. Available from: http://www.moph.gov.lb

11. Tenforde MW, Olson SM, Self WH, Talbot HK, Lindsell CJ, Steingrub JS, et al. Effectiveness of Pfizer-BioNTech and Moderna Vaccines Against COVID-19 Among Hospitalized Adults Aged $\geq 65$ Years - United States, January-March 2021. MMWR Morb Mortal Wkly Rep. 2021 May 7;70(18):674-9.

12. Tenforde MW, Patel MM, Ginde AA, Douin DJ, Talbot HK, Casey JD, et al. Effectiveness of SARS-CoV-2 mRNA Vaccines for Preventing Covid-19 Hospitalizations in the United States. Clin Infect Dis Off Publ Infect Dis Soc Am. 2021 Aug 6;ciab687.

13. Bajema KL, Dahl RM, Prill MM, Meites E, Rodriguez-Barradas MC, Marconi VC, et al. Effectiveness of COVID-19 mRNA Vaccines Against COVID-19-Associated Hospitalization - Five Veterans Affairs Medical Centers, United States, February 1August 6, 2021. MMWR Morb Mortal Wkly Rep. 2021 Sep 17;70(37):1294-9. 
medRxiv preprint doi: https://doi.org/10.1101/2022.01.19.22269514; this version posted January 24, 2022. The copyright holder for this preprint (which was not certified by peer review) is the author/funder, who has granted medRxiv a license to display the preprint in perpetuity.

All rights reserved. No reuse allowed without permission.

14. Tenforde MW. Sustained Effectiveness of Pfizer-BioNTech and Moderna Vaccines Against COVID-19 Associated Hospitalizations Among Adults — United States, March-July 2021. MMWR Morb Mortal Wkly Rep [Internet]. 2021 [cited 2021 Dec 17];70. Available from: https://www.cdc.gov/mmwr/volumes/70/wr/mm7034e2.htm

15. Bernal JL, Andrews N, Gower C, Robertson C, Stowe J, Tessier E, et al. Effectiveness of the Pfizer-BioNTech and Oxford-AstraZeneca vaccines on covid-19 related symptoms, hospital admissions, and mortality in older adults in England: test negative case-control study. BMJ [Internet]. 2021 May 13 [cited 2022 Jan 6];373. Available from: https://www.bmj.com/content/373/bmj.n1088

16. Self WH. Comparative Effectiveness of Moderna, Pfizer-BioNTech, and Janssen (Johnson \& Johnson) Vaccines in Preventing COVID-19 Hospitalizations Among Adults Without Immunocompromising Conditions - United States, March-August 2021. MMWR Morb Mortal Wkly Rep [Internet]. 2021 [cited 2021 Dec 17];70. Available from: https://www.cdc.gov/mmwr/volumes/70/wr/mm7038e1.htm

17. Hyams C, Marlow R, Maseko Z, King J, Ward L, Fox K, et al. Effectiveness of BNT162b2 and ChAdOx1 nCoV-19 COVID-19 vaccination at preventing hospitalisations in people aged at least 80 years: a test-negative, case-control study. Lancet Infect Dis. 2021 Nov 1;21(11):1539-48.

18. Chung H, He S, Nasreen S, Sundaram ME, Buchan SA, Wilson SE, et al. Effectiveness of BNT162b2 and mRNA-1273 covid-19 vaccines against symptomatic SARS-CoV-2 infection and severe covid-19 outcomes in Ontario, Canada: test negative design study. BMJ. 2021 Aug 20;374:n1943.

19. Merhi G, Trotter AJ, Martins L de O, Koweyes J, Le-Viet T, Naja HA, et al. Replacement of the Alpha variant of SARS-CoV-2 by the Delta variant in Lebanon between April and June 2021 [Internet]. 2021 Aug [cited 2021 Dec 20] p. 2021.08.10.21261847. Available from: https://www.medrxiv.org/content/10.1101/2021.08.10.21261847v1

20. CDC. COVID-19 Vaccination [Internet]. Centers for Disease Control and Prevention. 2020 [cited 2021 Dec 20]. Available from: https://www.cdc.gov/coronavirus/2019ncov/vaccines/fully-vaccinated-guidance.html 